\title{
Size and receptor density of glutamatergic synapses: a viewpoint from left-right asymmetry of CA3-CA1 connections
}

\author{
Yoshiaki Shinohara ${ }^{1 *}$ and Hajime Hirase $e^{1,2 *}$ \\ Hirase Research Unit, RIKEN Brain Science Institute, Wako, Japan \\ 2 Saitama University Brain Science Institute, Saitama, Japan
}

Edited by:

Masahiko Watanabe, Hokkaido

University, Japan

Reviewed by:

Masanori Matsuzaki, The University of

Tokyo, Japan

Dmitri A. Rusakov, University College

London, UK

\section{${ }^{*}$ Correspondence:}

Yoshiaki Shinohara and Hajime Hirase,

Hirase Research Unit, RIKEN Brain

Science Institute, 2-1, Hirosawa, Wako,

Saitama 351-0198, Japan.

e-mail: shinohara@brain.riken.jp

hirase@brain.riken.jp

\begin{abstract}
Synaptic plasticity is considered to be the main mechanism for learning and memory. Excitatory synapses in the cerebral cortex and hippocampus undergo plastic changes during development and in response to electric stimulation. It is widely accepted that this process is mediated by insertion and elimination of various glutamate receptors. In a series of recent investigations on left-right asymmetry of hippocampal CA3-CA1 synapses, glutamate receptor subunits have been found to have distinctive expression patterns that depend on the postsynaptic density (PSD) area. Particularly notable are the GluR1 AMPA receptor subunit and NR2B NMDA receptor subunit, where receptor density has either a supralinear (GluR1 AMPA) or inverse (NR2B NMDAR) relationship to the PSD area. We review current understanding of structural and physiological synaptic plasticity and propose a scheme to classify receptor subtypes by their expression pattern with respect to PSD area.
\end{abstract}

Keywords: spines, glutamate, AMPAR, NMDAR, mGluR5, PSD

\section{INTRODUCTION}

It is generally agreed that synaptic transmission is the most prevalent way neurons communicate. In the cerebral cortex and hippocampus, a great majority (80-90\%) of the neurons use glutamate as neurotransmitter and hence form excitatory synapses (Somogyi et al., 1998). Long-term synaptic plasticity is realized by changes in the expression of functional molecules at the synapse. A large number of studies suggest long-term potentiation (LTP) is induced by coincident occurrences of action potentials in the presynaptic neuron and depolarization of the postsynaptic neuron, which results in activation of postsynaptic NMDARs (Malenka and Bear, 2004, for a review). In CA1 pyramidal cell synapses, $\mathrm{Ca}^{2+}$ influx into postsynaptic spines through the activated NMDARs leads to mobilization of cytoskeletal proteins (Kuriu et al., 2006; Okamoto and Hayashi, 2006; Okamoto et al., 2004), and insertion of AMPARs (Park et al., 2004; Shi et al., 1999). Enlargement of the spines is reported to occur after LTP (Engert and Bonhoeffer, 1999; Matsuzaki et al., 2004).

The NMDARs and AMPARs are both comprised of distinct subunits. NMDARs have a heterotetrameric structure with two NR1 subunits and various combinations of two NR2(A-D) subunits (Clements and Westbrook, 1991; Furukawa et al., 2005; Nakanishi, 1992; Yashiro and Philpot, 2008). Among NR2 subtype combinations, NR2A-NR2A and NR2B-NR2B are the most predominant NMDAR compositions in the cerebral cortex and hippocampus. Both NR2A- and NR2B-containing NMDARs are present in synapses, whereas extrasynaptic NMDARs are predominantly NR2B type (Scimemi et al., 2004; Stocca and Vicini, 1998; Tovar and Westbrook, 1999; but also see Miwa et al., 2008). Activation of NR2B-containing NMDARs by synchronized synaptic input is suggested to be a means for local communication among neighboring spines (Scimemi et al., 2004). AMPARs are tetrameric receptors that have dimer of dimers composition (Rosenmund et al., 1998).
GluR1, GluR2, and GluR3 constitute the majority of AMPARs in mature CA3-CA1 excitatory synapses. Most of these AMPARs contain GluR2 subunits (i.e., GluR1/GluR2 or GluR2/GluR3 composition), making the receptors impermeable to $\mathrm{Ca}^{2+}$ (Adesnik and Nicoll, 2007; Derkach et al., 2007).

As synaptic efficacy to a large extent depends on postsynaptic receptor quantity (but also see Enoki et al., 2009; Ward et al., 2006), it is of utmost interest and importance to identify the rules that govern the receptor expression pattern and synapse/spine morphology. Recent findings on the left-right asymmetrical hippocampal CA3-CA1 projection provide some insight as to how synaptic receptor density might relate to postsynaptic density (PSD) area. That is, in this system ionotropic glutamate receptor density varies in an orderly fashion, depending on the lateral origin of the innervating axon.

\section{ASYMMETRICAL SYNAPTIC SIZE AND RECEPTOR DISTRIBUTION}

Afferent input to CA1 stratum radiatum is classically known to be composed of two different pathways: the Schaffer collaterals that originate from the ipsilateral CA3 pyramidal cells and the commissural projections that originate from the contralateral CA3 pyramidal cells. One of the interesting features of these synapses is that ipsilateral projections display different physiological properties in left and right hippocampi in mice (Kawakami et al., 2003). For instance, synapses formed by the left Schaffer collaterals in stratum radiatum are more sensitive to NR2B NMDAR antagonists than those in the right side. Western blots of CA1 stratum radiatum PSD fraction show NR2B is nearly 50\% more densely expressed in the left side in mice (Figure 1A) (Kawakami et al., 2003; Shinohara et al., 2008; Wu et al., 2005). Therefore, this asymmetry provides a convenient model system for studying differential postsynaptic receptor subunit allocation, resultant synaptic plasticity, and trafficking of PSD proteins. 


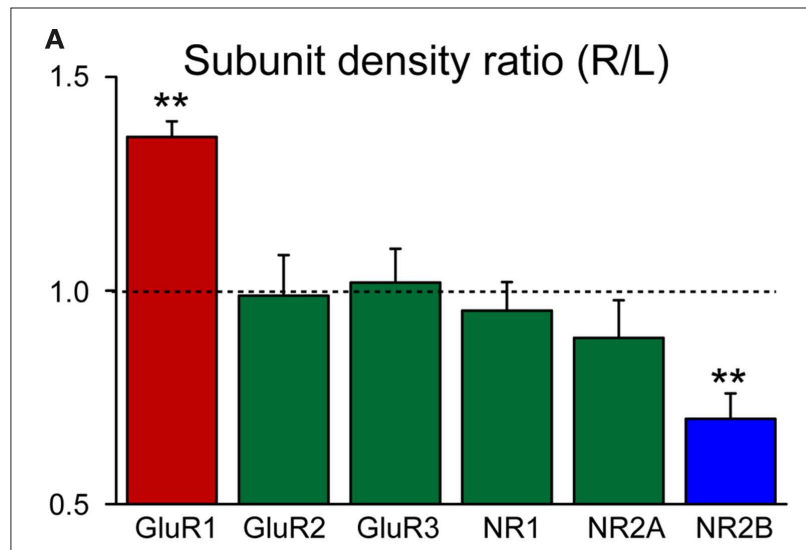

B
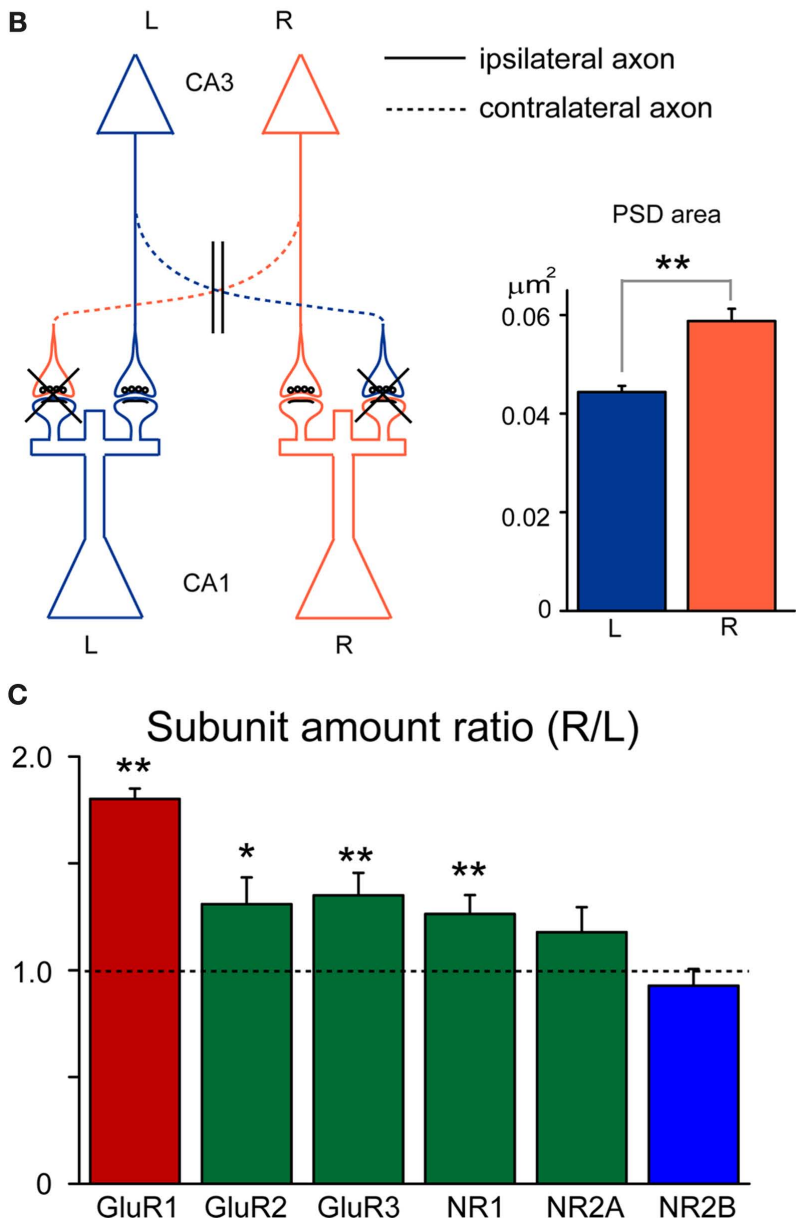

FIGURE 1 | Right-left (R/L) ratios of ipsilateral synaptic glutamate receptor proteins in hippocampal CA1 stratum radiatum. (A) Original densitometry $\mathrm{R} / \mathrm{L}$ ratio (data taken from Kawakami et al., 2003; Shinohara et al., 2008). Among major ionotropic glutamate receptors, NR2B and GluR1 ratios show significant left-right differences $\left({ }^{*} p<0.01\right)$. (B) Schematic figure of CA3-CA1 hippocampal projections (left). In investigating only ipsilateral projections, contralaterally projecting axons were excluded from analysis by ventral hippocampal commissure transection. Average PSD areas of ipsilateral CA3-CA1 projections (right). Ipsilateral synapses in left side are generally smaller (** $p<0.01$ ). (C) R/L ratios were scaled by PSD area to estimate the relative receptor amounts per synapse. Most of the subunits showed significant left-right differences $\left({ }^{*} p<0.05,{ }^{*} p<0.01\right)$. L and $\mathrm{R}$ represent left and right sides, respectively.
We recently reinvestigated this system from an anatomical point of view (Shinohara et al., 2008). Serial section electron microscopic reconstruction revealed that right side Schaffer synapses have a 40\% larger PSD area (Figure 1B). Considering the previously reported asymmetric distribution of NR2B, one can therefore predict that NR2B-rich left Schaffer synapses are smaller. Further investigation using post-embedding serial electronmicroscopic reconstruction, however, suggested that the amount of synaptic NR2B receptor expression did notcorrelate with the PSD area. Electronmicroscopic investigation of immunolabeled synaptic surface suggests that the synaptic NR2B labeling density and exposed synaptic area (which roughly corresponds to the PSD area) are inversely (i.e., $1 / x$ ) related (Figure 2).

Although this finding appears incompatible with the previous result that more NR2B is observed in the left innervated CA1 stratum radiatum, it can be reconciled by interpreting PSD fraction western blotting as synaptic protein densities: Optical density measurements from a western blotting indicate protein amounts. In PSD fraction blotting, the samples are scaled by the total amount of protein contained in the PSD fraction. As the amount of PSD protein is well-correlated with the PSD area, the result of normalization can be interpreted as the synaptic protein density (protein quantity/PSD area). Accordingly, the western blot result represents that the average NR2B density is higher in synapses innervated by the left CA3. Such an interpretation is consistent with the finding that synapses innervated from the left CA3 are generally smaller.

Considering the size difference between left- and right-innervated synapses, the ratios of receptor subunit expression between left- and right-innervated synapses are calculated in Figure 1C. The analysis demonstrates that the amount of the NR2B subunit per synapse is similar in both CA1s. Interestingly, a contrasting expression pattern was observed for GluR1, in that the receptor density tends to increase with the PSD area. It is noteworthy that these findings conform to the idea of late-phase LTP where AMPARs are inserted into enlarged spines.

\section{PSD SIZE DEPENDENT EXPRESSION PATTERNS OF RECEPTORS AND THEIR ROLES IN PLASTICITY}

In light of the receptor density to size relationship demonstrated in hippocampal synapses, we propose that glutamate receptor subunits can be classified into three groups based on their expression patterns as regards to PSD area (Figure 3) - Group 1 the receptor density is inversely related to the PSD area (e.g., NR2B). Group 2 the receptor density is constant and hence the receptor expression can be estimated by a linear function of PSD area; Group 3 the receptor density increases with the PSD area (e.g., GluR1).

Among the three major NMDA receptor subunits, NR2B is the only subunit that belonged to Group 1 . This view is in agreement with a previous study that showed NR2B subunits are enriched in smaller synapses (Sobczyk et al., 2005). Interestingly, metabotropic glutamate receptor 5 (mGluR5), the major postsynaptic mGluR in CA3-CA1 synapses, shows a similar laterality-dependent expression pattern as NR2B (Figure 4) and hence is classified as Group 1. Four major subunits - GluR2, GluR3, NR1, and NR2A are categorized as members of Group 2. As the number of these subunits is linearly proportional to the PSD area, increase of the receptor subunits is 
A

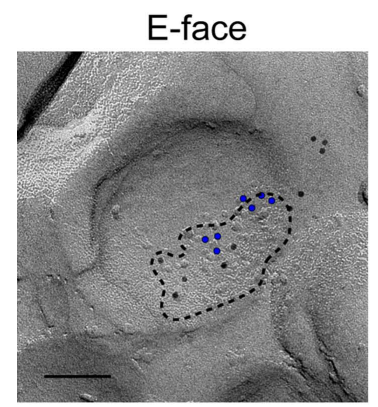

- NR2B

E-face

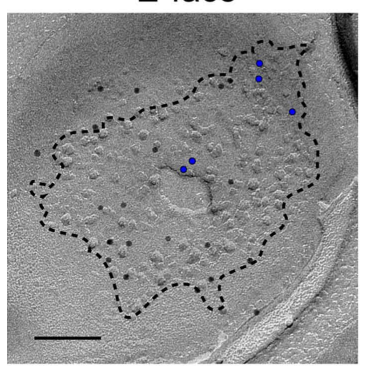

- NR2B

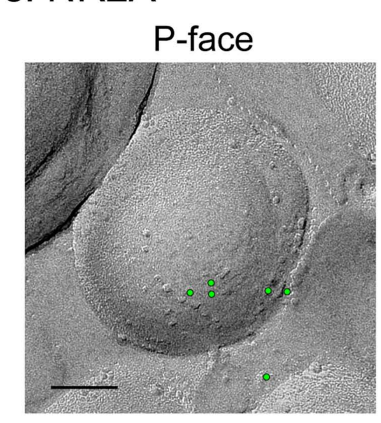

- NR2A

P-face

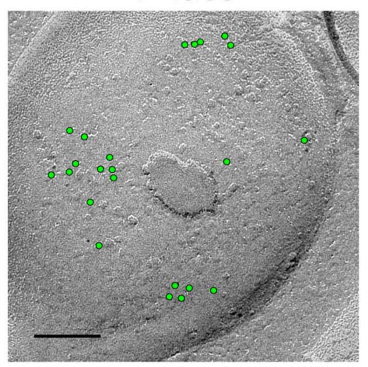

- NR2A
B

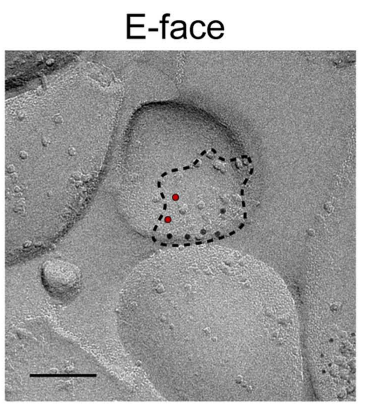

- GluR1

E-face

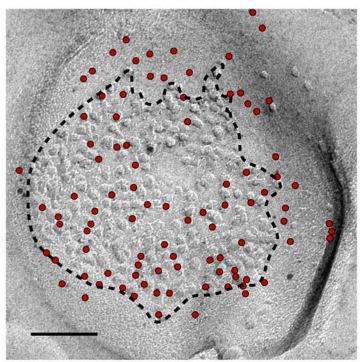

- GluR1
P-face

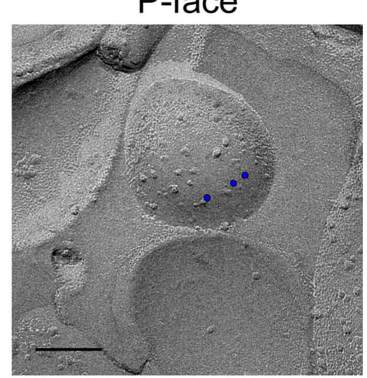

- NR2B

$P$-face

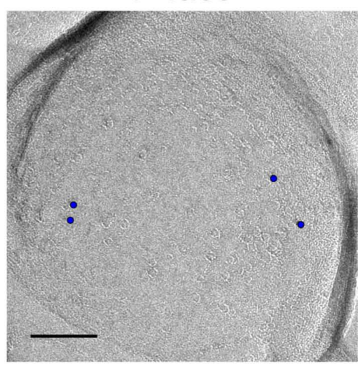

- NR2B
C

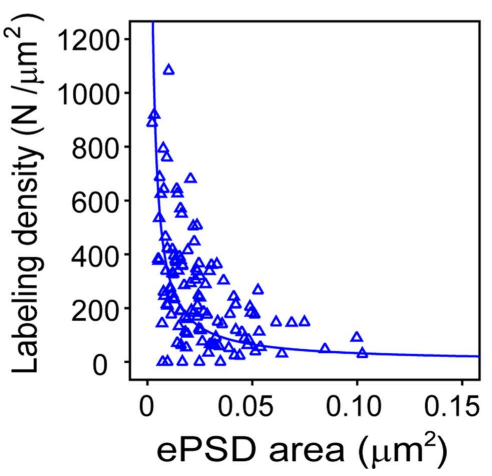

D

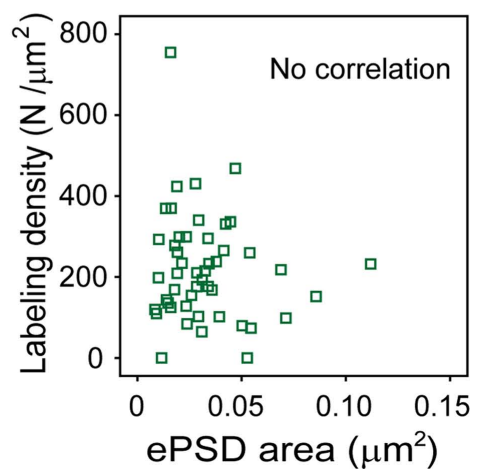

E

\section{GluR1}

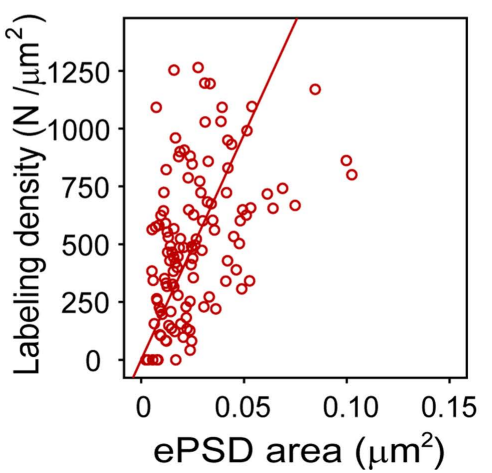

FIGURE 2 | Glutamate receptor subunits have distinct expression patterns according to PSD size. Examples of paired SDS-digested freeze-fracture replica labeling (SDS-FRL) for NR2B (E-face) vs. NR2A (P-face) (A), and for GluR1 (E-face) vs. NR2B (P-face) (B) in CA1 stratum radiatum synapses. Upper rows are examples of small synapses, whereas lower rows are that of large synapses. Large black dots present in all E-faces (10 nm gold) in (A, B) are NR1 labeling, which is used for a marker of synapses. Boundaries of intramembrane particles
(IMP) shown in dotted lines in E-faces correspond to exposed PSD areas (ePSD). Scale bars: $100 \mathrm{~nm}$. Relationship between the ePSD and density of synaptic NR2B (C), NR2A (D), or GluR1 (E) labeling, as assessed by SDS-FRL method. The data set published in Shinohara et al. (2008) is used in the analysis. Hyperbolic fit matches well for NR2B, whereas positive correlation is seen for GluR1. No significant correlation was observed for NR2A. For detailed descriptions of SDS-FRL, see Masugi-Tokita and Shigemoto (2007). a passive reflection of the volume change of the synapses. As far as we investigated, GluR1 is the only glutamate receptor subunit that shows a supralinear relationship to PSD area in the CA1 area. As the PSD area is linearly related to the spine volume (Harris and Stevens, 1989), the grouping holds valid for receptor expression vs. spine volume classification.

As relatively constant amounts of Group 1 molecules are expressed in a synapse regardless of the PSD area, it is tempting to regard them as "unbiased-sensor" glutamate receptors for synaptic plasticity. Indeed, NR2B expression declines only mildly during the developmental process (Liu et al., 2004; Nase et al., 1999), and the profound increase in the NR2A/NR2B ratio during development is mainly attributed to upregulation of NR2A subunits (Liu et al., 2004; Nase et al., 1999; Yashiro and Philpot, 2008). Therefore, in young animals where plastic changes of synapses are constantly taking place, activation of NR2B is thought to be critical to allow calcium influx into synapses in order to modify their efficacy. Likewise, activation of mGluR5 is essential in some forms of LTP (Lu et al., 1997; Rodrigues et al., 2002). Interestingly, both NR2B and mGluR5 are also known to be extrasynaptic receptor subunits 


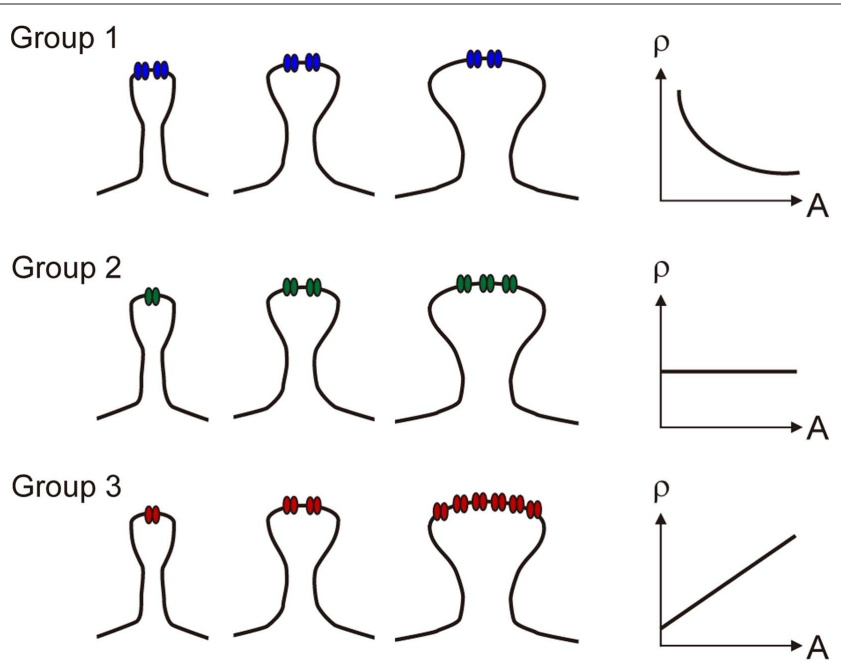

FIGURE 3 | Schematic drawings illustrating different ways in which receptor density ( $\mathbf{p}$ ) varies with postsynaptic spine area (A). In Group 1, receptor expression remains constant regardless of PSD area. In Group 2, receptor expression grows linearly with PSD area, and the receptor density is constant. In Group 3, receptor expression grows supralinearly with PSD area, as the receptor density is an incremental function of synapse area.

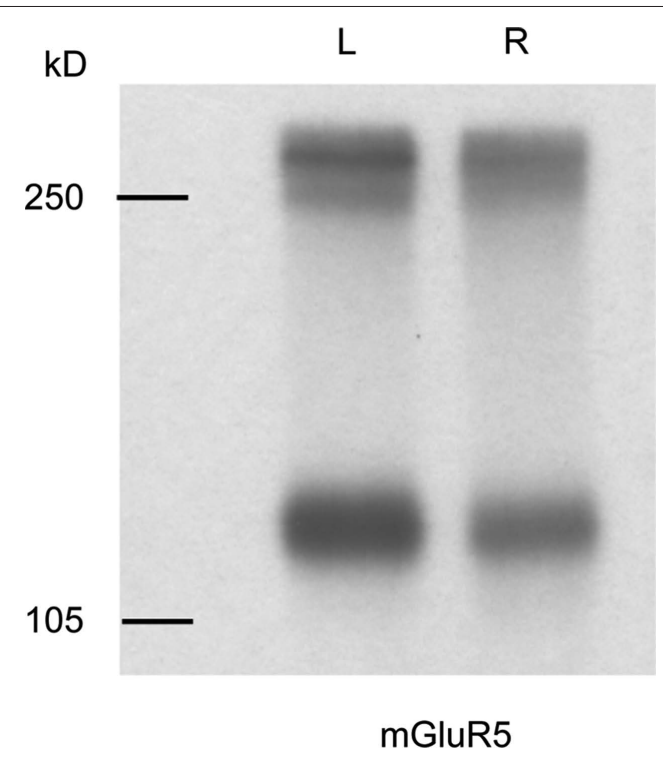

FIGURE 4 | mGluR5 shows a similar left-right distribution to NR2B in ventral hippocampal commissure transected mice. Immunoreactive bands were observed at approximately 130 and 260 kD, which represent monomeric and dimeric forms of mGluR5, respectively. Left side PSD preparation from ipsilateral CA3-CA1 projection contains more mGluR5 than that of right side. Molecular weights are shown in left in kilodalton.

(Lujan et al., 1996; Scimemi et al., 2004; Stocca and Vicini, 1998; Tovar and Westbrook, 1999).

As NR1 is an essential subunit of NMDAR, the question arises as to why NR1 and NR2B belong to different groups in our analysis. A parsimonious explanation is that the majority of NR2 subunits are NR2A in mature animals (Sans et al., 2000; Stocca and Vicini,
1998) and therefore the relationship between NR1 expression and synapse area is largely reflected by NR2A behavior.

What makes GluR1 special over other receptor subunits? In latephase LTP, AMPARs increase in number while NMDARs elicit little change (Malinow and Malenka, 2002). Electron microscopic studies also demonstrate that NMDAR immunoreactivity at a spine correlates little with the synapse area (Racca et al., 2000; Takumi et al., 1999). At the same time, LTP-inducing stimulations result in a morphological enlargement of the spine (Matsuzaki et al., 2004). Because of the supralinear receptor expression vs. synapse area relationship, GluR1 is likely to be actively involved in the expression of synaptic potentiation, in clear contrast to the subunits that belong to Group 2.

Overwhelming increase of GluR1 over GluR2 in large spines essentially results in an increase of non-GluR2-containing AMPARs, in particular homotetrameric GluR1 receptors (Wenthold et al., 1996). As the presence of GluR2 in AMPAR determines $\mathrm{Ca}^{2+}$ impermeability, AMPAR mediated $\mathrm{Ca}^{2+}$ influx should be present in large and GluR1-dense synapses. Indeed, a recent study demonstrated transient incorporation of GluR2-lacking AMPAR into stimulated synapses during LTP as well as the existence of pools of GluR2lacking AMPARs in hippocampal slice culture and acute slice, as well as in the cerebral cortex in vivo (Bagal et al., 2005; Clem and Barth, 2006; Plant et al., 2006). Although the $\mathrm{Ca}^{2+}$ permeability and functionality of these GluR2-lacking AMPA receptors remain controversial (Adesnik and Nicoll, 2007), a close look at electron micrographs of SDS-digested synaptic membrane surface for GluR1 shows that multiple 5-nm immunogold particles are often found around a single intramembrane particle cluster. Perhaps the densely distributed immunogold particles observed in CA1 stratum radiatum synapses are indicative of GluR1 homomeric receptors (Figure 5, for an example). It is worth noting, however, that such large synapses represent only a small fraction of hippocampal CA1 synapses. In large spines, GluR1/GluR1 homotetramer AMPARs potentially serve as a source of $\mathrm{Ca}^{2+}$ entry, in addition to NMDR and voltage gated calcium channels, to keep the synapse potentiated. In smaller excitatory synapses, stimulation by ligands leads to a large elevation of $\mathrm{Ca}^{2+}$ concentration via relatively dense NR2Bcontaining NMDARs.

\section{CONCLUDING REMARKS}

Studies with perfusion-fixed tissues clearly showed abundance of GluR1 subunits in large synapses, which is consistent with the observation that synaptic insertion of the GluR1 C-terminus permits a stable increase in hippocampal pyramidal cell spine volume (Kopec et al., 2007). Formation of GluR1-enriched synapses appears to be well-correlated with memory formation, as recent experiments have demonstrated experience-dependent recruitment of GluR1 in the barrel cortex (Takahashi et al., 2003), amygdala (Rumpel et al., 2005), and hippocampus (Matsuo et al., 2008). Moreover, in vivo imaging studies demonstrated that large spines are structurally stable over several days or longer in mature sensory cortex (Grutzendler et al., 2002; Holtmaat et al., 2005; Trachtenberg et al., 2002). On the other hand, an in vitro study suggested that incorporation of GluR2 lacking AMPAR occurs transiently in a time scale of tens of minutes (Plant et al., 2006) and that GluR1-containing AMPARs are later replaced by GluR2/GluR3 AMPARs (Hayashi 

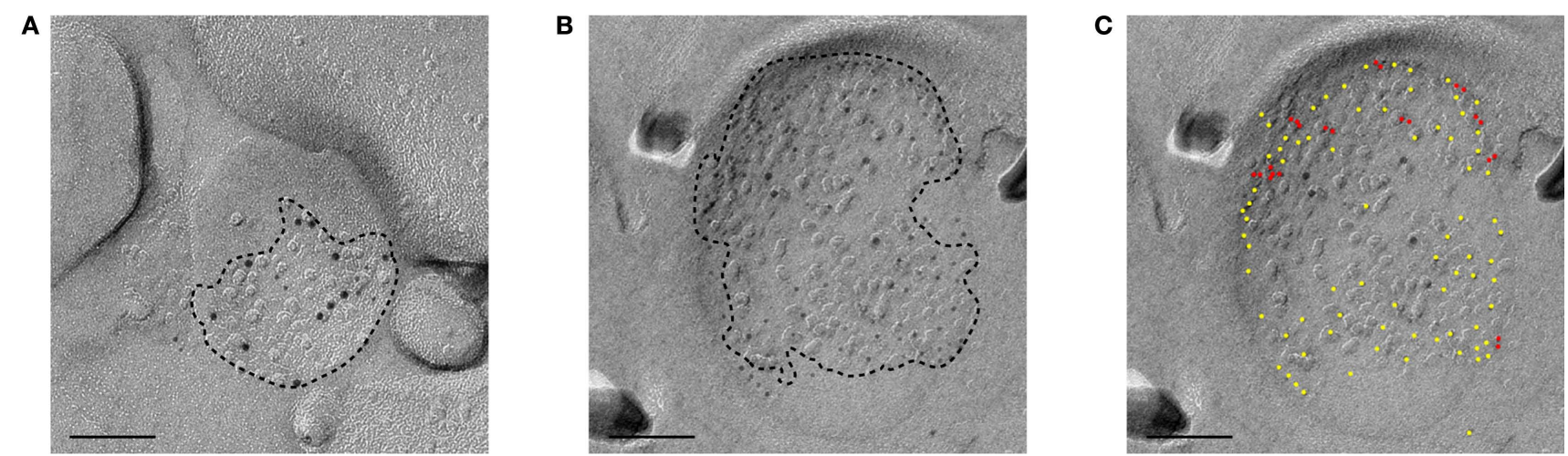

FIGURE 5 | Electronmicrographs showing SDS-FRL labeling of the GluR1 and NR1 subunits of a small synapse $(A)$ and a large synapse $(B)$ in CA1 stratum radiatum. PSD areas are demarcated by dotted lines. GluR1 is labeled by $5 \mathrm{~nm}$ immunogold particles and NR1 is labeled by $10 \mathrm{~nm}$ immunogold particles. GluR1 is more densely distributed in the large synapse. (C) GluR1 labeling in (B) is labeled by yellow or red dots. Gold particles with inter-particle distance $<10 \mathrm{~nm}$ is labeled in red. Scale bar: $100 \mathrm{~nm}$ et al., 2000; Shi et al., 2001). No doubt, the precise dynamics of different glutamate receptor subtypes, synapse size, and functional significance shall eventually be resolved by the use of molecular tools and fine resolution imaging techniques such as PALM (Micheva and Smith, 2007) and STED (Hell et al., 2004). Given the hypothesis that large spines are "memory spines" and small spines are "learning spines” (Kasai et al., 2003; Matsuzaki, 2007), large spines represent a small fraction (10-30\%) of total synapses (Harris and Stevens, 1989; Konur et al., 2003; Shinohara et al., 2008). In vivo imaging of GluR1-homotetramer provides a potentially key approach for observing memory formation in individual synapses. Finally, one shall not dismiss the possibility that synaptic plasticity can occur entirely by changes in the presynaptic terminal, as demonstrated in use-dependent synaptic plasticity experiments (Maccaferri et al., 1998; Scott and Rusakov, 2006; Weisskopf and Nicoll, 1995; Xiang et al., 1994) and simultaneous monitoring of the spine $\mathrm{Ca}^{2+}$ level and somatic membrane potential using the sharp intracellular electrode

\section{REFERENCES}

Adesnik, H., and Nicoll, R. A. (2007). Conservation of glutamate receptor 2-containing AMPA receptors during long-term potentiation. J. Neurosci. 27 , 4598-4602.

Bagal, A. A., Kao, J. P., Tang, C. M., and Thompson, S. M. (2005). Long-term potentiation of exogenous glutamate responses at single dendritic spines. Proc. Natl. Acad. Sci. USA 102, 14434-14439.

Clem, R. L., and Barth,A. (2006). Pathwayspecific trafficking of native AMPARs by in vivo experience. Neuron 49 , 663-670.

Clements, J. D., and Westbrook, G. L. (1991). Activation kinetics reveal the number of glutamate and glycine binding sites on the $\mathrm{N}$-methyl-D-aspartate receptor. Neuron 7, 605-613.

Derkach, V.A., Oh, M.C., Guire, E. S., and Soderling, T. R. (2007). Regulatory mechanisms of AMPA receptors in synaptic plasticity. Nat. Rev. Neurosci. 8, 101-113.

Engert, F., and Bonhoeffer, T. (1999). Dendritic spine changes associated with hippocampal long-term synaptic plasticity. Nature 399, 66-70. Fine, A. (2009). Expression of longterm plasticity at individual synapses in hippocampus is graded, bidirectional, and mainly presynaptic: optical quantal analysis. Neuron 62, 242-253.

Furukawa, H., Singh, S. K., Mancusso, R., and Gouaux, E. (2005). Subunit arrangement and function in NMDA receptors. Nature 438, 185-192.

Grutzendler, J., Kasthuri, N., and Gan, W. B. (2002). Long-term dendritic spine stability in the adult cortex. Nature 420, 812-816.

Harris, K. M., and Stevens, J. K. (1989). Dendritic spines of CA 1 pyramidal
Enoki, R., Hu, Y. L., Hamilton, D., and

method (Enoki et al., 2009; Ward et al., 2006). The degree to which the exclusively "presynaptic" plasticity occurs in vivo during learning and memory is unknown. However, recalling that cholinergic receptor dynamics was successfully monitored in neuromuscular junction synapses in vivo (McCann et al., 2008), one can anticipate only a short delay before it becomes possible to observe glutamatergic receptor subunit dynamics in the central nervous system in vivo.

\section{ACKNOWLEDGEMENTS}

We thank Yasunori Hayashi, Rafael Yuste, Thomas Launey, Kathleen Rockland, Ryuichi Shigemoto, and Tadaharu Tsumoto for their advice on early versions of the manuscript. The data presented in the manuscript were obtained in the National Institute of Physiological Sciences (Shigemoto lab), Okazaki, Japan. Hajime Hirase and Yoshiaki Shinohara are supported by HFSP (RGY0073/2006-C) and KAKENHI (21650081 and 21700440).

cells in the rat hippocampus: serial electron microscopy with reference to their biophysical characteristics. J. Neurosci. 9, 2982-2997.

Hayashi,Y., Shi, S.H., Esteban, J. A., Piccini, A., Poncer,J.C., and Malinow, R. (2000). Driving AMPA receptors into synapses by LTP and CaMKII: requirement for GluR1 and PDZ domain interaction. Science 287, 2262-2267.

Hell, S.W., Dyba, M., and Jakobs, S. (2004). Concepts for nanoscale resolution in fluorescence microscopy. Curr. Opin. Neurobiol. 14, 599-609.

Holtmaat, A. J., Trachtenberg, J. T. Wilbrecht, L., Shepherd, G. M. Zhang, X., Knott, G. W., and Svoboda, K. (2005). Transient and persistent dendritic spines in the neocortex in vivo. Neuron 45 279-291.

Kasai, H., Matsuzaki, M., Noguchi, J., Yasumatsu, N., and Nakahara, H.
(2003). Structure-stability-function relationships of dendritic spines. Trends Neurosci. 26, 360-368.

Kawakami, R., Shinohara, Y., Kato, Y., Sugiyama, H., Shigemoto, R., and Ito, I. (2003).Asymmetrical allocation of NMDA receptor epsilon2 subunits in hippocampal circuitry. Science 300 , 990-994.

Konur, S., Rabinowitz, D. Fenstermaker, V. L., and Yuste, R. (2003). Systematic regulation of spine sizes and densities in pyramidal neurons. J. Neurobiol. 56, 95-112.

Kopec, C. D., Real, E., Kessels, H. W., and Malinow, R. (2007). GluR1 links structural and functional plasticity at excitatory synapses. J. Neurosci. 27, 13706-13718.

Kuriu, T., Inoue, A., Bito, H., Sobue, K., and Okabe, S. (2006). Differential control of postsynaptic density scaffolds via actin-dependent and 
-independent mechanisms. J. Neurosci. 26, 7693-7706

Liu, L., Wong, T. P., Pozza, M. F., Lingenhoehl, K., Wang, Y., Sheng, M., Auberson, Y.P., and Wang, Y.T. (2004). Role of NMDA receptor subtypes in governing the direction of hippocampal synaptic plasticity. Science 304, 1021-1024.

Lu, Y.M., Jia, Z., Janus, C., Henderson, J. T., Gerlai, R., Wojtowicz, J. M., and Roder, J. C. (1997). Mice lacking metabotropic glutamate receptor 5 show impaired learning and reduced CA1 long-term potentiation (LTP) but normal CA3 LTP. J. Neurosci. 17, 5196-5205.

Lujan, R., Nusser, Z., Roberts, J. D., Shigemoto, R., and Somogyi, P. (1996). Perisynaptic location of metabotropic glutamate receptors mGluR1 and mGluR5 on dendrites and dendritic spines in the rat hippocampus. Eur. J. Neurosci. 8, 1488-1500.

Maccaferri, G., Toth, K., and McBain, C. J. (1998). Target-specific expression of presynaptic mossy fiber plasticity. Science 279, 1368-1370.

Malenka, R. C., and Bear, M. F. (2004). LTP and LTD: an embarrassment of riches. Neuron 44, 5-21.

Malinow, R., and Malenka, R. C. (2002). AMPA receptor trafficking and synaptic plasticity. Annu. Rev. Neurosci. 25, 103-126.

Masugi-Tokita, M., and Shigemoto, R. (2007). High-resolution quantitative visualization of glutamate and GABA receptors at central synapses. Curr. Opin. Neurobiol. 17, 387-393.

Matsuo, N., Reijmers, L., and Mayford, M. (2008). Spine-type-specific recruitment of newly synthesized AMPA receptors with learning. Science 319, 1104-1107.

Matsuzaki, M. (2007). Factors critical for the plasticity of dendritic spines and memory storage. Neurosci. Res. $57,1-9$.

Matsuzaki, M., Honkura, N., EllisDavies, G. C., and Kasai, H. (2004). Structural basis of long-term potentiation in single dendritic spines. Nature $429,761-766$.

McCann, C. M., Tapia, J. C., Kim, H., Coggan, J. S., and Lichtman, J. W. (2008). Rapid and modifiable neurotransmitter receptor dynamics at a neuronal synapse in vivo. Nat. Neurosci. 11, 807-815.

Micheva, K. D., and Smith, S. J. (2007). Array tomography: a new tool for imaging the molecular architecture and ultrastructure of neural circuits. Neuron 55, 25-36.
Miwa, H., Fukaya, M., Watabe, A. M., Watanabe, M., and Manabe, T. (2008). Functional contributions of synaptically localized NR2B subunits of the NMDA receptor to synaptic transmission and long-term potentiation in the adult mouse CNS. J. Physiol. 586, 2539-2550.

Nakanishi, S. (1992). Molecular diversity of glutamate receptors and implications for brain function. Science 258, 597-603.

Nase, G., Weishaupt, J.,Stern, P., Singer, W., and Monyer, H. (1999). Genetic and epigenetic regulation of NMDA receptor expression in the rat visual cortex. Eur. J. Neurosci. 11, 4320-4326.

Okamoto, K., and Hayashi, Y. (2006). Visualization of F-actin and G-actin equilibrium using fluorescence resonance energy transfer (FRET) in cultured cells and neurons in slices. Nat. Protoc. 1, 911-919.

Okamoto, K., Nagai, T., Miyawaki, A., and Hayashi, Y. (2004). Rapid and persistent modulation of actin dynamics regulates postsynaptic reorganization underlying bidirectional plasticity. Nat. Neurosci. 7, 1104-1112.

Park, M., Penick, E. C., Edwards, J. G., Kauer, J. A., and Ehlers, M. D. (2004). Recycling endosomes supply AMPA receptors for LTP. Science 305, 1972-1975.

Plant, K., Pelkey, K. A., Bortolotto, Z. A., Morita,D., Terashima,A.,McBain, C. J., Collingridge, G. L., and Isaac, J. T. (2006). Transient incorporation of native GluR2-lacking AMPA receptors during hippocampal long-term potentiation. Nat. Neurosci. 9, 602-604.

Racca, C., Stephenson, F. A., Streit, P. Roberts, J. D., and Somogyi, P. (2000). NMDA receptor content of synapses in stratum radiatum of the hippocampal CA1 area. J. Neurosci. 20, 2512-2522.

Rodrigues, S. M., Bauer, E. P., Farb, C. R., Schafe, G. E., and LeDoux, J.E. (2002). The group I metabotropic glutamate receptor mGluR5 is required for fear memory formation and long-term potentiation in the lateral amygdala. J. Neurosci. 22, 5219-5229.

Rosenmund, C., Stern-Bach, Y., and Stevens, C. F. (1998). The tetrameric structure of a glutamate receptor channel. Science 280, 1596-1599.

Rumpel, S., LeDoux, J., Zador, A., and Malinow, R. (2005). Postsynaptic receptor trafficking underlying a form of associative learning. Science $308,83-88$.

Sans,N.,Petralia, R.S.,Wang,Y. X.,Blahos, J. II, Hell, J. W., and Wenthold, R. J. (2000). A developmental change in
NMDA receptor-associated proteins at hippocampal synapses. J. Neurosci. 20, 1260-1271.

Scimemi, A., Fine, A., Kullmann, D. M. and Rusakov, D. A. (2004). NR2Bcontaining receptors mediate cross talk among hippocampal synapses. J. Neurosci. 24, 4767-4777.

Scott, R., and Rusakov, D. A. (2006) Main determinants of presynaptic $\mathrm{Ca}^{2+}$ dynamics at individual mossy fiber-CA3 pyramidal cell synapses. J. Neurosci. 26, 7071-7081.

Shi, S., Hayashi, Y., Esteban, J. A., and Malinow, R. (2001). Subunit-specific rules governing AMPA receptor trafficking to synapses in hippocampal pyramidal neurons. Cell 105, 331-343.

Shi, S. H., Hayashi, Y., Petralia, R. S., Zaman, S. H., Wenthold, R. J., Svoboda, K., and Malinow, R. (1999). Rapid spine delivery and redistribution of AMPA receptors after synaptic NMDA receptor activation. Science 284, 1811-1816.

Shinohara, Y., Hirase, H., Watanabe, M., Itakura, M., Takahashi, M., and Shigemoto, R. (2008). Left-right asymmetry of the hippocampal synapses with differential subunit allocation of glutamate receptors. Proc. Natl Acad. Sci. USA 105, 19498-19503.

Sobczyk, A., Scheuss, V., and Svoboda, K. (2005). NMDA receptor subunitdependent $\left[\mathrm{Ca}^{2+}\right]$ signaling in individual hippocampal dendritic spines. J. Neurosci. 25, 6037-6046.

Somogyi, P., Tamas, G., Lujan, R., and Buhl, E. H. (1998). Salient features of synaptic organisation in the cerebral cortex. Brain Res. Brain Res. Rev. 26 113-135.

Stocca, G., and Vicini, S. (1998). Increased contribution of NR2A subunit to synaptic NMDA receptors in developing rat cortical neurons. J. Physiol. 507(Pt 1), 13-24.

Takahashi, T., Svoboda, K., and Malinow, R. (2003). Experience strengthening transmission by driving AMPA receptors into synapses. Science 299, 1585-1588.

Takumi, Y., Ramirez-Leon, V., Laake, P., Rinvik, E., and Ottersen, O. P. (1999). Different modes of expression of AMPA and NMDA receptors in hippocampal synapses. Nat. Neurosci. 2, 618-624.

Tovar, K. R., and Westbrook, G. L. (1999). The incorporation of NMDA receptors with a distinct subunit composition at nascent hippocampal synapses in vitro. J. Neurosci. 19 4180-4188.
Trachtenberg,J.T., Chen,B.E., Knott, G. W. Feng, G., Sanes, J. R., Welker, E., and Svoboda, K. (2002). Long-term in vivo imaging of experience-dependent synaptic plasticity in adult cortex. Nature 420, 788-794.

Ward, B., McGuinness, L., Akerman, C. J., Fine, A., Bliss, T. V., and Emptage, N. J. (2006). State-dependent mechanisms of LTP expression revealed by optical quantal analysis. Neuron 52, 649-661.

Weisskopf, M. G., and Nicoll, R. A. (1995). Presynaptic changes during mossy fibre LTP revealed by NMDA receptormediated synaptic responses. Nature 376, 256-259.

Wenthold, R. J., Petralia, R. S., Blahos, J. II, and Niedzielski, A.S. (1996). Evidence for multiple AMPA receptor complexes in hippocampal CA1/CA2 neurons. J. Neurosci. 16, 1982-1989.

Wu, Y., Kawakami, R., Shinohara, Y., Fukaya, M., Sakimura, K., Mishina, M., Watanabe, M., Ito, I., and Shigemoto, R. (2005). Target-cell-specific left-right asymmetry of NMDA receptor content in Schaffer collateral synapses in epsilon1/NR2A knock-out mice. J. Neurosci. 25, 9213-9226.

Xiang, Z., Greenwood, A.C., Kairiss, E. W., and Brown, T. H. (1994). Quantal mechanism of long-term potentiation in hippocampal mossy-fiber synapses. J. Neurophysiol. 71, 2552-2556.

Yashiro, K., and Philpot, B. D. (2008). Regulation of NMDA receptor subunit expression and its implications for LTD, LTP, and metaplasticity. Neuropharmacology 55, 1081-1094.

Conflict of Interest Statement: The authors declare that the research was conducted in the absence of any commercial or financial relationships that could be construed as a potential conflict of interest.

Received: 22 April 2009; paper pending published: 09 May 2009; accepted: 16 June 2009; published online: 01 July 2009.

Citation: Shinohara Y and Hirase H (2009) Size and receptor density of glutamatergic synapses: a viewpoint from left-right asymmetry of CA3-CA1 connections. Front. Neuroanat. (2009) 3:10. doi: 10.3389/neuro.05.010.2009

Copyright (c) 2009 Shinohara and Hirase. This is an open-access article subject to an exclusive license agreement between the authors and the Frontiers Research Foundation, which permits unrestricted use, distribution, and reproduction in any medium, provided the original authors and source are credited. 